\title{
Business analytics: new concepts and trends
}

DOI: 10.7595/management.fon.2019.0013

\section{Abstract:}

Research question: In the last decade, the concept of Business analytics (BA) has gone through revolutionary changes. It has gained a lot in popularity and attracted immense interest both in academic and commercial communities. Accepting this reality, the main research topic of the paper is to investigate and present the global tendencies regarding the development of business analytics concept. Motivation: We have been motivated by huge changes in ICT environment and have studied how they reflect on the domain of Business analytics. Idea: The main idea was to elaborate and make distinction between crucial characteristics of the classical and new emerging concepts of Business analytics. In addition to technical aspects, the broader business context of all presented concepts and phenomena are discussed. Findings: Dealing with essential elements of the BA concept, this paper points out that the history of Business analytics has been strongly influenced by the changes and innovations in the sphere of information communications technologies (ICT). In particular, the paper addresses two tendencies connected to the status of Business analytics in the digital economy. The first tendency concerns the emergence of Big Data phenomenon and its implications on both business and public environment. The other tendency concerns the increasing business request and need for data and analytics democratization. The paper concludes that specifically two forms of analytics - embedded analytics and self-service analytics - appeared as strong enablers of the process of data and analytics democratization. Contribution: Although a considerable part of the paper tackled the issue of the ICT trends and its impact on the business analytics, one specific part of the paper presents the broader business implications of data and analytics deployment. Our opinion is that this part provides a significant contribution to the BA topic. We demonstrate that there is strong evidence that one of the most important benefits that BA brings to the company is competitive advantage. Also, it is emphasized that the other big issue in business domain concerns the forms of BA deployment in the organization. We strongly support the opinion that successful BA deployment requires a clear data and analytics strategy, with elements of proposed ICT innovations and BA solutions.

Keywords: business analytics, information-communication technologies (ICT), big data, democratization of analytics, open data initiative, embedded analytics, self-service analytics

JEL classification: M15, M21, C80

\section{Introduction}

The concept of Business analytics (BA) may be regarded as a result of an interaction of a few research disciplines and software tools: quantitative data analysis - statistical analysis, management science techniques and methods, computer science and information communication technology (ICT) tools. Although the development of all these disciplines reflects on the progress of the BA concept, it is not exaggerated to say that the dynamic changes in ICT domain have the dominant influence on the BA.

In the last ten years, we have been witnesses to a very dynamic development of Business analytics. As it was pointed out by Davenport and Harris in the period after 2006, a revolution in Business analytics has happened (Davenport \& Harris, 2017). The authors explained this revolution mainly as a set of huge changes in the ICT domain, which had a powerful impact on BA. They emphasized that in the last decade the development of Business analytics and its applications in business processes have gone through a few historical phases, which they noted as "four eras in ten years": from the Analytics 1.0 to the Analytics 4.0 . 
The phase of Analytics 1.0 refers to the period when all classical analytical tools have been used. This period spanned from the mid of the last century until 2005. The focus of this BA concept was on the usage of descriptive statistical methods, optimization and simulation techniques, classical reporting capabilities and the visual data presentations. In this long period, different techniques from statistical domain and other quantitative disciplines, as well as from management science were extensively explored for the purpose of business analytics. The final goal of the BA usage was to provide support for business decision making, and the people included in this process were mainly separated: data analysts on the one side and business decision makers on the other side. The huge change happened at the mid of the previous decade. The period from 2005 to 2012 is characterized by the emergence of the Big data phenomenon and the shift in the analytics toward the Big Data analytics as a specific standalone entity. This phase which refers to the rise of Big Data is marked as Analytics 2.0. The pioneering proponents of this BA era were Google, Yahoo, Microsoft, eBay, Facebook, Linkedln etc., whose business models were, and still are, based on the data gathering, manipulating and analyzing. Their main products are data products and services. In the last few years (2012 until nowadays) much of the analytics efforts have been focused on the combined usage of the previous two analytical capabilities, which was annotated as an Analytics 3.0. Often, this era is characterized as a mixture of "Big and small data": big firms are engaged in dealings with big data and small firms have a lot of potential dealings with classical - small data analytics. The objective of the firms in this era is not only to use BA for decision support, but also to create new products and services. The final Analytics 4.0 era is at its beginning. In comparison with the previous three eras, this era has some specifics: while in the eras of Analytics 1.0 to Analytics 3.0 the role of the human analyst is of crucial importance, the Analytics 4.0 is more autonomous. Despite the need for specific professionals, such as quantitative analysts and data scientists, which are the workhorse of the first three analytics eras, the Analytics 4.0 is more oriented to the democratization of the analytics jobs. New job positions are emerging, such as: citizen data scientists and business translators. Artificial intelligence, machine learning and cognitive computing are the new technologies that promise to radically change a classical BA paradigm. Nowadays, all described BA types are living and functioning in practice side by side.

The structure of the paper is as follows. After the introduction, in the second section of the paper, the classical concept of Business Analytics is discussed, with the focus on the definition of the term, key features and different types of business analytics. The next section elaborates the topic of the modern tendencies regarding the information communication technologies and their impact on BA. In particular, the Big Data phenomenon and the process of data and analytics democratization are discussed. The fourth section deals with business implications of data analytics usage, covering two issues: the link between BA and company's competitive advantage and main challenges of Business analytics deployment. The fifth section presents the future trends of business analytics. Finally, in the sixth section concluding remarks on the main findings are made.

\section{Classical Concept of Business Analytics: Definition of the Term and Key Features}

The classical concept of Business analytics encompasses different tools, techniques and processes with the purpose of analyzing business data and extracting some new patterns, trends and/or insights that provide additional business values. One definition of BA explains it as "a process of transforming data into actions through analysis and insights in the context of organizational decision making and problem solving" (Evans, 2017, p.30). According to the Gartner definition "Business analytics is comprised of solutions used to build analysis models and simulations to create scenarios, understand realities and predict future states. Business analytics includes data mining, predictive analytics, applied analytics and statistics, and is delivered as an application suitable for a business user" (Gartner IT Glossary, 2018).

The classical approach to business analytics has been around for a long period. It differentiates between three distinct types of analytics: descriptive, predictive and prescriptive analytics (Schniederjans, Schniederjans \& Starkey, 2015, pp.18-20). The relationship between these types is not competitive, but primarily complementary. Each of these analytics is focused on specific business problems and provides specific solutions. The focus of the descriptive analytics is on the past events - it tries to give the answer to the following question: What happened in the past? This type of analytics is referred to as a post-festum (post-mortem) analytics and is based mainly on the usage of descriptive statistical techniques. Today, most of business analytics still belongs to this analytics type.

Predictive analytics is oriented to the future and to the question: What will happen in the future? This type of analytics combines the historical data with different quantitative techniques, algorithms and rules to estimate the probability or the likelihood of the future situations and business outcomes (Siegel, 2016). Often 
this analytics is referred to as a form of an advanced analytics with the usage of the techniques, such as: trend and regression analysis, forecasting, multivariate statistical techniques, data mining techniques pattern matching, estimation and prediction (Gartner IT Glossary, 2018). The final goal of the predictive analytics is to reveal patterns in data that should serve as a base for prediction of customers' behaviour, as well as the features of products, services and markets.

Finally, prescriptive analytics is concentrated on the problems of optimization and simulation looking for the answer to the following question: What can we do to improve the business outcomes? This analytics goes further than the predictive analytics, as it aims to provide not only prediction, but also an adequate decision options and the relevant implications of each decision. It includes data, mathematical and computational models and business rules, which are derived from the existing business processes. Here, data are internal and external, i.e., they are coming from inside organization, as well as from the outside business environment. Also, this analytics uses hybrid data - structured and unstructured data. Further on, the used mathematical and computational models are more complex and belong to the following scientific disciplines: applied statistics, operational research (simulations, optimization techniques, and game theory), machine learning, artificial intelligence, decision science theory, natural language processing, image processing, computer vision and metaheuristics.

The final component of prescriptive analytics comprises business rules, which are relevant and derived from the business processes. More precisely, they are extracted from the business strategy, policies and preferences, and present the objective constraints and boundaries, best practical examples and so on.

The main features and characteristics of the three classical analytics types could be summarized by the following short schemes:

Descriptive analytics:

Data + Model (mainly descriptive statistics) $=$ Description of the past (1)

Predictive analytics:

Data + Model (predictive statistics) $=$ Prediction oriented to the future (2)

Prescriptive analytics:

Data (structured and unstructured) + Model (complex models from various domains) + Rules $=$ Prediction + Decision + Recommendation of the action + Advice

Nowadays descriptive and predictive analytics are dominant in practice. Prescriptive analytics does not appear in its full force, it is still in its infancy phase and is considered as a technology of the future analytics. As Basu (2013) remarked, prescriptive analytics is one of revolutionary technologies that will be the main business topic in the upcoming years. Further on, he noted and discussed five crucial attributes of the prescriptive analytics (Basu, 2013, p. 8):

1. Hybrid data;

2. Integrated predictions \& prescriptions;

3. Prescriptions \& side effects;

4. Adaptive algorithms;

5. Feedback mechanism.

One of the key features of Prescriptive analytics technology is its ability to process hybrid data, i.e., combination of structured, semi-structured and unstructured data. The evolution of analytics regarding the data type may be found in an extended text and graphic sources suggested by Gartner (Basu, 2013).

Besides the traditional quantitative techniques and technologies which are suitable for structured data processing, hybrid data demand essentially new technologies to be processed. That is a signal and image processing, natural language processing, computer vision and more.

Apart from this basic BA classification, some additional and/or modified types of analytics can be found in the literature. One additional BA framework is composed of four analytics types. In addition to the classical three analytics - descriptive, predictive and prescriptive analytics, it also includes the diagnostic analytics or inquisitive analytics. These two terms are used with an equal meaning (Schniederjans, et al., 2015; Gartner IT Glossary, 2018; Vlamis, 2015; Kuipers, 2014; Cornerstone Glossary, 2018). Diagnostic analytics is closely related to descriptive analytics and is mainly concerned with the past events and partly with the present 
situation. While the descriptive analytics is trying to give answer to the question: What happened in the past, the diagnostic analytics is dealing with the following question: Why something happened in the past? Usually the answer is provided by testing the business hypothesis, which includes the usage of statistical analysis, factor analysis, and so on.

Recently, one more term has been widely used. It is advanced analytics. It has a broader meaning than the particular BA types. While the traditional analytical tools are mainly related to the descriptive statistical analysis of historical business data, tools of the advanced analytics are oriented to the future and comprise predictive analytics, data mining, location or spatial data analysis, big data analytics, to name a few of analytical tools that belong to the advanced analytics. Gartner definition of advanced analytics points out that it includes sophisticated quantitative methods from the domain of an advanced statistics, data mining, machine learning, simulation and optimization to produce patterns, trends and insights that traditional approaches are not capable to produce (Gartner BI and Analytics Report, 2016).

\section{How Modern ICTs Reflect on Business Analytics?}

The importance of information communication technologies as an integral part of the concept of business analytics has already been emphasized in the previous section. Although many of ICT innovations, directly or indirectly, reflect on the business analytics, further on in this paper only two tendencies from the ICT domain that have substantial impact on business analytics, are discussed: the phenomenon of Big data revolution and the process of democratization of public and business data and analytics.

\subsection{The Big data phenomenon and streaming analytics}

The concept of the Big data attracted a a lot of attention in the global ICT society and academic community in the last decade. The rapid - almost an explosive increase in data volume (sometimes called a tsunami of data) is without precedent in the history of data gathering and storage. According to the IBM estimates, the annual growth rate of data volume was $40 \%$ in the recent few years and $90 \%$ of all data produced in the long period of the human civilization have been produced in the last 2 years (IBM Software Group, White paper, 2015, p.5). It is, also, amazing evidence that more than 2,500 petabytes of data are created every day (SAS Institute, Inc., 2017a). Further on, it is estimated by Entrepreneur.com, that by 2020, every individual, who is online, will create every second almost $1.7 \mathrm{Mb}$ of new data, which will result of $44 \mathrm{Zb}$ (Zettabyte $=10^{21}$ byte) of data by that time.

This explosive data growth is mainly the result of the ICT tendency to the global computer connections through the networks of people (a number of social networks), things (Internet of Things - IOT) and processes. Also, some other technologies, such as Global Positioning Systems and Geographical Information Systems, as well as the technology of Radio Frequency Identification - RFID, have contributed to the enormous increase in data volume in all spheres of work and life (Dietrich, Heller, \& Yang, 2015).

There is no unique definition of this phenomenon, but the dominant definition of Big data put into focus the three Vs: Volume, Variety and Velocity of data (Zikopoulos, Eaton, de Roos, Deutch, \& Lapis, 2012, pp. 2536). In addition to the substantial enlargement in data volume, the other characteristic - Variety, of data reflects the various data forms and data sources from which data come from. In comparison with the traditional structured data (electronic data tables, spreadsheet data editors, relational databases, etc.), the volume of semi-structured (log files, XML, e-mail, etc.) and unstructured data (video, images, audio data, data on social networks and so on) has increased more rapidly. According to the IBM findings, more than $80 \%$ of all data volume which is currently generated belongs to the semi-structured and unstructured data (Basu, 2013 , p. 8). The third characteristic - Velocity, refers to the dynamic nature of Big data processing. While the previous computing paradigm was based on the processing of static data, the new computing paradigm based on Big data technology allows the processing of dynamic data streams (Ghosh, 2016).

The Big data phenomenon brings significant novelties and changes in the business sector and public domain. More on this topic may be found in the paper written by Chroneos-Krasavac, Soldic-Aleksic and Petkovic (2016). Staying on the ground of business analytics the most serious impact of Big data on business analytics reflects on the new version of business analytics which was born. That is the streaming analytics, i.e., analytics on „data-in-motion“. So, nowadays we can compare the classical business analytics concept, based on the "stock“ of data - data-at-rest (i.e., data stored in, data bases and data warehouses), with the Big data analytics concept, which is based on the flow of data - "data-in-motion“ (data generated by 
sensors, RFID and various devices - mobile, as well as the flow of data on social networks). As an important feature of the streaming analytics is its ability to provide data processing in real time, this analytics is also known as a real-time big data analytics.

As it was explained in the introduction part of the paper, in the periods of Analytics 2.0 and Analytics 3.0 eras the focus was on a Big data concept. The main characteristics of Analytics 3.0. can be summarized as follows (Davenport \& Dyche, 2013, pp. 27-30):

- Different data sources and types enter the analytical process;

- Variety of IT architectures (clustered servers of Hadoop, traditional data base) are used;

- Faster big data technologies and data processing will mature and be employed;

- Analytics models are being integrated and embedded into business applications;

- New IT professions and roles emerged, such as: data analysts, data scientists, data engineers and data translators. Also, in addition to Chief Data Officer and Chief Information Officer, a new role of Chief Analytics Officers appeared;

- While the classical analytics is focused mainly on descriptive and predictive analytical models, modern analytics tends to take advantages of prescriptive analytics.

The usage of big data concept and real-time analytics makes room for substantial changes in business processes and public services. It is estimated by SAS that $89 \%$ organizations look at the Big Data as an important business opportunity, but only $3 \%$ of organizations consider their data management systems as adequate for big data processing (SAS Institute, Inc., 2017b). For business organizations, this means that if they want to have better performance and be in the leading position in the industry, they have to face serious challenges, otherwise they will end up losing opportunities and consequently lagging behind the competitors (Chen, Preston \& Swink, 2015). Therefore, one crucial question may be posed: Do Big data and analytics bring better business performance? An extensive analysis of this topic and the answer to the question can be found in the paper Big Data: the Management Revolution, written by Mc Afee, et al., (2012). The authors led a team which was focused on the investigation of the usage of data and analytics in business decision making and the consequent business performance. They tested the following hypothesis: data-driven companies are better performers compared to the companies that do not rely on the data in business running? Their conclusion was that data-driven organizations have better business performance than other organizations. Further on, they specified: „companies in the top third of their industry in the use of data-driven decision making were, on average, $5 \%$ more productive and $6 \%$ more profitable than their competitors (Mc Afee et al., 2012, p.6).

\subsection{Democratization of data and business analytics}

The usage of Big data across various business functions is a great challenge for managers at all business levels and layers. To take advantage of Big data requires a specific set of skills which are incorporated into a new profession - data scientist. It is estimated that nowadays only the United States experiences the shortage of 190.000 data scientists (Srujana, Sharma \& Amitava, 2016, p.43). Besides that, in many companies, a large part of useful business data are concentrated in the ICT departments and only ICT staff and a number of executive managers have an access to data and analytics. This is a severe limitation for management to get full business benefits across all the levels of the enterprise. In this respect Srujana et al. $(2016$, p. 43) pointed out that "democratization of data and analytics is the next promising frontier for business success and data economy". The term data democratization relates to the possibility of the end user to access data in any digital format. It means making data and analytical tools available and accessible to people who need them at all organizational layers. That way organizations could improve business decision-making and make it dynamic and decentralized. There is no unique solution regarding the level of centralization and decentralization of data and analytics which is adequate for different organizations. The tendency of democratization of data and analytics does not have the same meaning for all businesses. It opens the space for organizations to reconsider and recalibrate the right mix of centralization and decentralization suitable for their own needs. The real scale of data democratization in a particular company heavily depends on the corporate culture and management decisions. Although the topic of data democratization is primarily the managerial issue, it is worth mentioning that some technical advances, such as advances in virtualization, data federation software and cloud data storage, can contribute to the data sharing in organization.

The practice of democratization of non-business data and analytics has already been accepted in many public organizations, primarily governmental institutions. Some of the well-known examples of public data discovery platforms are Find The Data and Socrata websites. Socrata is a public cloud-based platform that 
provides government data to all public users in the United States, allowing them to use, discover and analyze data related to the cities, counties, states and the federal level (Tyler Technologies, Inc. 2018). Besides the free access to the public data, Socrata allows consumers to use analytical tools to gain insights from the data.

In this context, we refer to the Open data initiatives that have been taking ground in many countries, regions and cities. The idea on open data initiative is very similar to the established practice of open source software, open hardware and the similar (Kitchin, 2014). Governments of many cities, states and countries are fostering the open data initiative for public data and have established the appropriate websites (Kassen, 2017). The first open data portal was established in May 2009, by the US government administration.

In addition, from the very beginning, the idea was adopted by many international organizations such as the World Bank, the United Nations, the International Monetary Fund and the European Commission - EU Open Data Portal and Public Data Portal (Gray, 2014). The general framework and support for the open data initiative in Serbia is provided by the UNDP project "Open data - Open possibilities". The project started in 2015 and resulted in the open data portal of the Republic of Serbia activated at the beginning of October 2017 (Open Data Portal of the Republic of Serbia, 2018). The progress of the certain countries in the field of open data activities and their achievements may be followed at the international score lists, such as: Global Open Data Index and Open Data Barometer. Serbia is ranked as 41st in 2018 Global Open Data Index among 94 countries. The Index calculation is based on the level of data openness of the following indicators: Government Budget, Government Spending, National Laws, Draft Legislation, National Statistics, Administrative Boundaries, Procurement, Air Quality, Company Register, National Maps, Election Results, Weather Forecast, Locations, Water Quality and Land Ownership. More details on the Index structure and a country's position may be found at Global open data Index web site (Global Open Data Index, 2018).

Open data portals have powerful impact at both macro and micro-economic levels (Berends, Carrara, \& Radu, 2017). The main economic benefits of open data are reflected in: improved efficiency and quality of public administration, higher transparency of public services, new business models and innovative business services, as well as various significant social contributions. It is estimated by the European Commission that open data initiatives will contribute to the growth of EU data economy up to EUR 739 billion by 2020, which accounts for $4 \%$ of the EU GDP. The Economic Value of Open data for the EU member states may be summarized as follows: direct market size of $€ 325$ billion for the period 2016-2020, 100.000 jobs in Open Data in 2020 and z 1.7 billion cost savings for the public sector in 2020 (Open Data Barometer, 2016, pp.34). Another study revealed the open data potential in the following areas - Consumer finance, Consumer products, Health care, Oil and gas, Education, Electricity and Transportation. It reveals that the economic potential of open data in these domains is approximately \$ 3 - 5 trillion per year (Manyika, Chui, Farrell, Van Kuiken, Groves, \& Almasi Doshi, 2013, p. 9). Apart from direct economic benefits, it is believed that open data portals should encourage the creative business initiatives and foster knowledge economy development. Also, it is important to note that the Open data entrepreneurial ecosystem could not exist without support, i.e., it must be permanently encouraged and cultivated (Walker \& Simperl, 2018).

As valuable enablers of data and analytics democratization an open source platforms (such as Hadoop) and programming languages (for example R) have appeared. On the other hand, on the BA's market there are lots of BA producers that provide distributed models for analytics, as well as easy-to-use and flexible interfaces to users' legacy systems. More on this topic can be found in Gartner annual report on Magic Quadrant for business Intelligence and Analytics Platform (Gartner BI and Analytics Report, 2017). Additionally, it is evident that serious steps have been made to integrate the embedded analytics into business applications. Therefore, the embedded analytics is considered to be the future of Business Intelligence (Eckerson, 2016, pp. 9-13).

The wave of democratization of data and business analytics has brought some new roles in the business world. Here we point out the citizen data scientists and business translators. A citizen data scientist is neither an ICT specialist, nor an expert from the field of statistics or analytics. Rather, it is a person who is skillful in data handling and manipulation, as well as in creating models with analytical software. Thanks to a new breed of BA software solutions, the citizen data scientists are taking a more powerful and growing role in completing BA tasks without requiring a data science degree (Gartner BI and Analytics Report, 2016). Business translators are persons from the operation business levels in the organization who possess business knowledge and the general understanding of ICT. Their task is to make good connection between ICT professionals and business people. According to the Forrester report acceleration in the trend towards democratization of data usage and data analysis will continue. Their study shows that in 2015 almost $51 \%$ of business decision makers who used data and analysis in decision-making process have no problem in accessing data and their analysis without the help of ICT staff. The prediction is that this trend will continue and very soon reach the figure of $70 \%$ (Mc Cormick, 2016, p. 2). 


\subsection{Embedded analytics}

The wave of democratization of the BA concept brings new forms of analytics inclusion in business applications: embedded analytics and self-service analytics. As it was earlier pointed out, the main purpose of BA is to elicit some knowledge and insight from data. In this regard the concept of BA may be considered as an integral part of the wider concept of Business intelligence (BI). The subject relating to the relationship between Business intelligence and Business analytics is examined by Heinze, J. (Heinze, 2016).

While the traditional $\mathrm{BI}$ concept was mainly report and dashboard oriented with possibilities for reactive actions, embedded analytics brings a new perspective: not only reports, queries and dashboards, but also the analytical models and outputs are embedded into applications. This way the concept of $\mathrm{BI}$ is being transformed from a reactive to a proactive set of business tools.

The history of development of Business Intelligence tools, techniques and concept can be observed as an evolution process rather than the revolution one. It is presented at the Figure 1 (Eckerson, 2016).

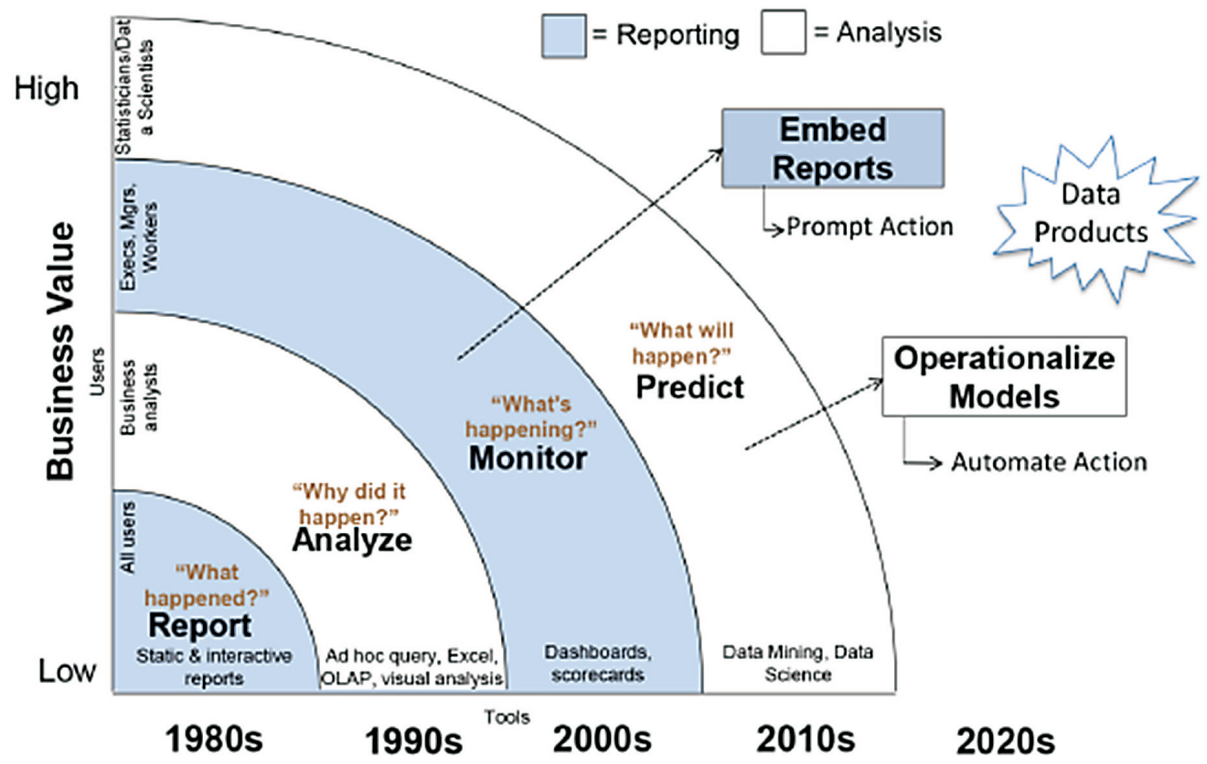

Figure 1. The evolution of $\mathrm{BI}$ - and its future (Source: Eckerson, 2016, p. 4.)

It is evident that the $\mathrm{BI}$ concept has been developing in two directions: the first is concentrated on the reporting functionalities, while the other focuses on the analysis. These two functionalities address the different classes of users: the first report-centric BI functionality has been oriented toward the casual users, while the other one - analysis-centric to data professionals and more powerful users. The final phase of $\mathrm{BI}$ evolution is a mixture of these two capabilities. It generates embedded reports and operationalized models. These two outputs are supposed to be actionable, i.e., to produce a prompt and automatic action in business environment.

According to the Gartner definition of embedded analytics, it is concerned with the usage of reporting and analytic programming features in transactional business applications. These features can be stored as functionalities inside the application or outside it (residing in some other system). However, the main point is that they must be easily accessible to users, without a need to change the system $(, 2018)$.

What kind of tools and functionalities do organizations embed into their applications? Generally, it could be a set of the following functionalities:

- Charts and components (static report and/or report's parts, tables, queries, maps etc.);

- Dynamic reports and dashboards, that provide an interactivity for the users;

- Transaction execution (apart from analytical capabilities some BI tools can provide also the transaction execution);

- Predictive analytics that encompasses various advanced analytical models and techniques;

- Self-service analytics - aimed to the power users for data extraction, classification, visualization and making specific reports and/or dashboards. 
Having in mind the technological characteristics of the embedded $\mathrm{Bl}$ it may be concluded that it is not a new phenomenon. On the contrary, it has been around for a long period. The following table presents the main features of this technology in the last three decades.

Table 1. Embedded $\mathrm{BI}$ - time perspective

\begin{tabular}{|c|c|c|c|}
\hline Period & Platform & Data Source & User features \\
\hline 1990 s & Desktop & Files, RDBMS & Static Reports \\
\hline $2000 s$ & Web & OLAP, XML & Dynamic-interactive Reports, Dashboards, OLAP \\
\hline 2010 s & Cloud & $\begin{array}{c}\text { Big data, Hadoop, NoSQL, } \\
\text { Cloud apps, streams, server logs }\end{array}$ & Predictive and self-service analytics \\
\hline
\end{tabular}

Source: Authors modified the illustration presented in Eckerson Group Report, (Eckerson, 2016, p.10)

Generally speaking, the embedded analytics uses different analytic features that are incorporated in transactional business applications. These analytical features may be part of application or be stored outside of applications, but it is important that the user can access them relatively easily, without switching different systems.

\subsection{Self-service analytics}

Embedded analytics paved the way for the self-service analytics usage. Namely, a new set of tools has emerged that help ordinary business users to prepare descriptive analysis and visual exploration of the data at their disposal. This idea is not new. It demonstrates that data analysis is not the job to be exclusively done by business analysts, but by an entire company work force. The proponents of the idea believe that data analysis jobs should be removed from the ICT departments to the business operation levels. So, it is expected that business professionals will be enabled to perform at least simple queries, data exploration and visualization and report generating. In line with this idea is the emergence of flexible and easy-to-use software tools and functionalities to handle and visualize data. Therefore, more intuitive, business centric analytical tools with flexible interfaces are taking the ground and promising to be available to the ordinary business users. That is the process of democratization of analytics.

As the new trend of the rise of self-service analytics (SSA) is getting momentum, the greatest challenge for the organizations is the existence of an adequate data governance policy which could provide highquality data that is easily accessible (Brunet, 2018). Some studies show that $55 \%$ of organizations with a very high level of adoption of self-service analytics have implemented a serious data governance strategy and rules (Krensky, 2015, p.3). Only this way the self-service analytics can provide a full potential for casual and power business users.

\section{Business Implications of Data Analytics Usage}

In the previous sections, the classical concept of BA is introduced and then the modern ICT trends and innovations, reflecting on the BA, are discussed. This section is expanding the scope of discussion in a broader business context. It tackles the issue of some business implications of Data analytics (DA) deployment.

\subsection{The link between BA and company's competitive advantage}

Many research studies dealing with the concept of BA, as well as the business practice, have shown that the usage of $B A$ is widespread across almost all company business functions. However, the most dominant influence of BA, of Advanced and Predictive Analytics (APA) in particular, is recorded in the sphere of marketing, sales, executive management, information technology and finance (Dresner Advisory Services, 2015). Among many statistical and other quantitative techniques, the most popular is the usage of the following techniques: regression techniques (linear, nonlinear and logistic regression), different clustering and classification techniques, descriptive statistical procedures, principal component analysis, support vector machine - SVM models, neural networks - NN models, decision tree models (C4.5, CHAID, random forests), language processing and sentiment analysis (Dresner Advisory Services, 2015). The usage of all these techniques provides companies with the substantial potential and possibilities for business success. According to some marketing studies, the main benefits that BA brings to the companies are: competitive advantage, which is seen as the most important benefit for business users (noted by $57 \%$ respondents), new revenue opportunities, increased profitability, improved customer service and cost savings (Ventana Research Report, 2015, p.7). 
The impact of BA on company's business running, in particular on the competitive advantage, was first presented in the well-known paper Competing on Analytics, prepared and written by Davenport, Cohen and Jacobson (2005), more than one decade ago. The paper was based on the research conducted with the purpose to investigate the relationship between the companies' usage of sophisticated analytics and their business performance. The research had been sponsored by the large ICT companies - SAS and Intel. The authors of the paper shed the light on the new specificity regarding the competition - competition based on the extensive use of analytics, data and fact-based decision making. They argued that this type of competition is not something new, yet it has only existed for the period of a few decades. This was particularly true for the finance industry, mainly financial investment and trading business, where organizations have been competing using analytics for a long period. This practice has been adopted by the other industries, such as consumer profiling and finance, retailing, telecommunications, marketing, tourism, supply chain management, insurance industry, entertainment and so on. Furthermore, analytics based competition has been spreading within organizations - from department units to enterprise-wide level. Describing the companies which are analytically oriented in conducting business processes, the authors of the research emphasized the most prominent attributes of these companies:

- A strong support of analytical-based decision making by senior executives;

- An extensive use of statistical methods, predictive analytics, optimization, simulation and other complex analytical methods;

- A widespread usage of the analytics not only in one business unit, but in multiple and cross-section units and business functions.

Based on the conducted survey the authors remarked that analytical competition is not simply "yes“ or "no" attribute. On the contrary, analytically oriented firms may pass through several phases in their analytical business orientation. The authors defined these phases as follows (Davenport et al, 2005, p. 4):

- Phase 1: Major Barriers;

- Phase 2: Local Activity;

- Phase 3: Vision Not Yet Realized;

- Phase 4: Almost There;

- Phase 5: Analytical Competitors.

One third of the organizations in the survey were positioned in the phase 5 , only $7 \%$ in phase 1 and about $20 \%$ in other phases each. The final conclusion derived from this research indicated that opportunities for analytical competition may be found in every industry. Consequently, the individual firm that did not recognize and embrace these opportunities is in a risky position to lag behind the competitors regarding crucial business performance.

\subsection{Main challenges of business analytics deployment}

As it was pointed out in the previous section, the flood of data generated by various devices is transforming the world around us and has a potential to change business data landscape in general. In that context a crucial practical issue for organization is the following: How to organize data flow and make it accessible to the potential users who will deliver business value? The critical part of the answer to the previous question is the implementation of the adequate data infrastructure and an efficient data analytics strategy. Data analytics could take a role of a paramount business differentiator that brings new insight-driven business models. These models are supposed to be data-focused models. In that respect, we recall the famous online companies, such as, Google, Facebook, Yahoo, Linkedln, Microsoft, etc., most of which are striking examples of organizations whose business processes are completely data driven. It could be observed that, in general, organizations empowered with this kind of business models have substantial potential to outperform the organizations without data analytics experience in business running. How much the organization can take advantage of this potential depends of its capacity to go through the process of digital transformation. In short, the process of digital transformation leads to the data and analytics driven organization which makes smarter decisions, has potential to act not only reactively, but rather more proactively, creates more accurate business forecast, and becomes more predictable and profitable.

How can one set out on the road to become a data driven organization? The first big issue for the organization is how it treats the available data. Many organizations are treating data and analytics as passive and static business resources. On the contrary, data and analytics must be treated as dynamic resources, capable to deliver real-time information to all line-of-business (LOB) managers and users. The next big issue for organization is: what is its current position on the "business analytics journey" (Shashikiran, 2018). Does it belong to the stage of descriptive analytics, or to the stages of more matured analytics - predictive, prescriptive or more sophisticated - an advanced analytics? This starting point reflects on the further activities 
and decisions which should be resolved, such as: the choice of the data and analytics infrastructure, creation and deployment of the renewed (or completely new innovative) data-centric services and products, expansion of the good practice across the organization, recruiting, training and allocation of human resources for data analytics assignments, etc.

To deal with the above issues the organization needs to make a well-defined data strategy, concerning the data and information quality, data security and governance, data integration and preparation, data exploration, etc. (DalleMule \& Davenport, 2017), as well as an analytics strategy. Both of these should be in line with the business strategy, or more precisely, should be an integral part of the business strategy.

The road that leads to data driven organization is usually full of bumps - technical and non-technical. The technical obstacles are connected to the data storage, data quality (Batini \& Scannapieco, 2016), the integration of data from different data sources, hardware and software platforms, human resources, etc. On the other hand, one of crucial non-technical impediments is the lack of data-driven mindset in the organization. In that respect, the most serious efforts should be put on the change of the cultural mindset in the organization (Edmonds, 2014). This change is supposed to be directed toward the more open datadriven patterns of decision making in all spheres of business running, which opens the door for the process of data and analytics democratization. The most common enablers of the process of data and analytics democratization are open data platforms, open source software platforms, as well as data virtualization and data federation software. Yet, there are substantial challenges to make this concept a reality. Namely, the process of data and analytics democratization requires a strong commitment of managers at all business levels. In particular, the top business management is supposed to provide the insurance that the data and analytics strategy would be put in practice. The final goal of this strategy may be the creation of the collective intelligence in the organization, which means free information sharing throughout the organization.

\section{The Future Trends of Business Analytics}

Regardless of the scope in which business organizations accept the BA concept, the majority of them are in a position to deal with the modern ICT innovations and consequently prepare for the future. What can they expect on the field of business analytics in the future? The future of business analytics is shaped by the following trends:

- The trend of exploring Big data structures will continue and will be the focal point for both academic research and commercial application. The whole world is facing a tsunami of data coming from different sources, usually at extremely high speed and in various formats;

- An algorithmic economy is getting on the power - looking for an adequate response to Big data phenomenon, organizations and other business subjects are forced to turn to the new algorithmic solutions derived from the field of machine learning $(M L)$, data mining (DM), cognitive computing, natural language processing (NLP) and deep learning (DL). To be successful in these endeavours organizations must be flexible in integrating different data and analytics architecture in seamlessly connected infrastructure;

- The widespread usage of mobile devices foster the explosive growth of mobile applications - so, an application economy enters the stable and more matured period of development;

- Visual analytics is on the rise. It becomes a lingua franca for various data professionals and ordinary business users. Therefore, many ICT vendors are preparing products and tools for data visualization;

- Cloud analytics has taken the ground and would be an acceptable solution for the growing number of organizations;

- On the hardware side, the inclusion of Graphics processing units (GPUs) is getting momentum, replacing CPUs that have been used for decades (Weldon, 2017);

- In addition, one of the crucial elements of the future of data analytics is the focus on the speed at which organizations could generate business value from the data sources. Real-time analytics is in demand for fast moving data - data-in-motion, as well for data-at-rest, to deliver business insights and responses;

- Streaming analytics (data manipulation and analysis on the fly), with appropriate tools, is entering the BA market space;

- Finally, the big challenge in the next years will be the usage of the Internet-of-things (loT) technology, which will have an essential impact on data gathering, storage and processing, as well as on data analysis at all organizational levels. 
Conclusion

In the last decade, the concept of Business analytics (BA) has gained a lot on the popularity and attracted immense interest both in academic and professional - commercial communities. It includes different tools, techniques and processes which are focusing on analyzing business data and extracting some new patterns, trends and/or insights, that provide additional business values.

Dealing with essential elements of the BA concept this paper points out that the history of Business analytics has been strongly influenced by the changes and innovations in the sphere of information communications technologies. The last decade was the most turbulent period, which has brought a set of huge changes in the ICT domain with a powerful impact on BA. In particular, the paper addresses two tendencies connected to the status of Business analytics in the digital economy. The first tendency concerns the emergence of the Big Data phenomenon and its implications to both business and public environments. The other tendency concerns the increasing business request and the need for data and analytics democratization. Data and analytics democratization can be defined as data and analytics resources at the disposal of the employees in accordance with their needs, at all organizational levels and layers. The paper concludes that specifically, two forms of analytics - embedded analytics and self-service analytics, appeared as strong enablers of the process of data and analytics democratization. Today this process is more or less in force.

Although a considerable part of the paper tackled the issue of the ICT trends and their impact on the business analytics, also the broader business implications of data and analytics deployment have been discussed. Regarding all the above, the connection between BA and company's competitive advantage was first considered. There is strong evidence that one of the most important benefits that BA brings to the company is competitive advantage. The other big issue concerns the forms of BA deployment in the organization. We strongly support the opinion that successful BA deployment requires a clear data and analytics strategy, with elements of proposed ICT innovations and BA solutions. An integral part of this strategy should be a plan (a roadmap or a guideline) which could lead the organization through the process of digital transformation. The final goal of digital transformation is the creation of a data driven organization which is characterized by a widespread usage of data and analytics for making smarter decisions. We emphasized that one of the critical impediments in the process of digital transformation may be the lack of data-driven mindset and culture in the organization. To overcome this problem the organization needs a strong support of managers at all business levels. In particular, the top business management is supposed to be consequential in creating and maintaining the atmosphere of BA acceptance throughout the organization.

Finally, we have presented the future BA trends. These trends reveal the essence of the new developing era of BA - Analytics 4.0, which is now at its beginning. Yet, the main algorithms and tools on which the Analytics 4.0 is based on, such as algorithms of machine learning, deep learning and cognitive computing, are far from the infancy stage. They are already in use and will gain momentum in the next period.

\section{Acknowledgements}

The authors gratefully acknowledge the financial support from the Ministry of Education, Science and Technology of the Republic of Serbia, Grant No. 179005.

\section{REFERENCES}

[1] Basu, A. (2013). Executive edge: Five pillars of prescriptive analytics success. Analytics, March/April 2013, 8-13, INFORMS, Retrieved from: http://analytics-magazine.org/executive-edge-five-pillars-of-prescriptive-analytics-success/

[2] Batini, C., \& Scannapieco, M. (2016). Data and Information Quality - Dimensions, Principles and Techniques, Springer International Publishing Switzerland, DOI 10.1007/978-3-319-24106-7

[3] Berends, J., Carrara, W., \& Radu, C. (2017). Analytical Report n9: The Economic Benefits of Open Data. European Data Portal. Retrieved from: https://www.europeandataportal.eu/sites/default/files/analytical report_n9_economic_benefits_of_open_data.pdf

[4] Brunet, P. (2018). The rise of self-service analytics. Analytics, January/February 2018, 34-40. INFORMS, Retrieved from: http://analytics-magazine.org/rise-self-service-analytics/

[5] Chen, D.Q., Preston, D. S. \& Swink, M. (2015). How the Use of Big Data Analytics Affects Value Creation in Supply Chain Management. Journal of Management Information Systems, 32(4), 4-39, DOI: 10.1080/07421222.2015.1138364

[6] Chroneos Krasavac, B., Soldic-Aleksic, J., \& Petkovic, G. (2016). The Big Data Phenomenon - the Business and Public Impact. Industrija, 44(2), 117-144, DOI: 10.5937/industrija44-10036

[7] Cornerstone Glossary (2018). Diagnostic Analytics. Retrieved from: https://www.cornerstoneondemand.com/glossary/diagnostic-analytics 
[8] DalleMule, L., \& Davenport, T. H. (2017). What's Your Data Strategy? Harvard Business Review, MayJune 2017, Retrieved from: https://hbr.org/2017/05/whats-your-data-strategy?referral=03759\&cm_vc=rr_item_page.bottom

[9] Davenport, H. T., Harris, J., \& Abney, D. (2017). Competing on Analytics: The New Science of Winning. Brighton: Harvard Business Review Press

[10] Davenport, H.T., Dyché, J. (2013). Big Data in Big Companies: Executive Summary. International Institute for Analytics, Sponsored by SAS Institute Inc. Retrieved from: https://www.sas.com/content/dam/SAS/en_us/doc/ research1/big-data-big-companies-executivesummary-106462.pdf

[11] Davenport, T., Cohen, D., \& Jacobson, A. (2005). Competing on Analytics. Babson Executive Education - Working Knowledge Research Center. Retrieved from: http://www.babsonknowledge.org/analytics.pdf

[12] Dietrich, D. Heller, B., \& Yang, B. (2015). Data Science and Big Data Analytics: Discovering, Analysing, Visualizing and Presenting Data. EMC Education Service. Indianapolis, Indiana: John Wiley \& Sons, Inc.

[13] Dresner Advisory Services. (2015). Advanced and Predictive Analytics (Market Study 2015). Wisdom of Crowds ${ }^{\circledR}$ Series, Licensed to Dell, Sponsored by Dell, LLC. Retrieved from: http://www.dresneradvisory.com

[14] Eckerson, W. W. (2016). Embedded Analytics: The Evolution of BI - and its Future. Eckerson Group. Retrieved from: https://www.opentext.com/file_source/OpenText/en_US/PDF/opentext-eckerson-sbembedded-bi-business-intelligence-en.pdf

[15] Edmonds, S.C. (2014). The Culture Engine: A Framework for Driving Results, Inspiring Your Employees, and Transforming Your Workplace. New Jersey: John Wiley \& Sons, Inc.

[16] Evans, R. J. (2017), Business Analytics - Methods, Models and Decisions. 2nd edition. London, England: Pearson Education Limited

[17] Gartner BI and Analytics Report (2016), Magic Quadrant for Advanced Analytics Platforms, February 2016

[18] Gartner BI and Analytics Report (2017). Magic Quadrant for Business Intelligence and Analytics Platform. Retrieved from: https://www.sisense.com/whitepapers/gartner-magic-quadrant-2017/

[19] Gartner IT Glossary, 2018, Retrieved from: https://www.gartner.com/it-glossary/

[20] Ghosh, J. (2016). Big Data Analytics: A Field of Opportunities for Information Systems and Technology Researchers. Journal of Global Information Technology Management, 19(4), 217-222, DOI: 10. 1080/1097198X.2016.1249667

[21] Global Open Data Index (2018) Place Overview - table view. Retrieved from: https://index.okfn.org/place/

[22] Gray, J., (2014). Towards a Genealogy of Open Data. Paper presented at the General Conference of the European Consortium for Political Research in Glasgow, 3-6th September 2014. Available at Social Science Research Network (SSRN). DOI: 10.2139/ssrn.2605828.

[23] Heinze, J. (2016). Business Intelligence vs. Business Analytics: What's The Difference? July 2016. Retrieved from: https://www.betterbuys.com/bi/business-intelligence-vs-business- analytics

[24] IBM Software (2015). Understanding big data so you can act with confidence. White paper ITPP in association with IBM,January 30, 2015, Retrieved from:

https://www.itproportal.com/tag/ibm-big-data/

[25] Kassen, M. (2017). Understanding transparency of government from a Nordic perspective: open government and open data movement as a multidimensional collaborative phenomenon in Sweden. Journal of Global Information Technology Management, 20(4), .236-275, DOI: 10.1080/1097198X.2017.1388696

[26] Kitchin, Rob (2014). The Data Revolution - Big Data, Open Data, Infractures \& Their Consequences. London: SAGE Publications Ltd, DOI: 10.4135/9781473909472

[27] Krensky, P. (2015). The Landscape of Self-Service Analytics. Aberdeen Group. Retrieved from: www.aberdeen.com

[28] Kuipers, E. (2014). Inquisitive Analytics - Mapad: the new way of thinking. Retrieved from: https://elsekuipers.wordpress.com/tag/inquisitive-analytics/

[29] Manyika, J., Chui, M., Farrell, D., Van Kuiken, S., Groves, P., \& Almasi Doshi, E. (2013). Open data: Unlocking innovation and performance with liquid information. McKinsey Global Institute. Retrieved from: https://www.mckinsey.com/business-functions/digital-mckinsey/our-insights/open-data-unlockinginnovation-and-performance-with-liquid-information

[30] Mc Afee, A., \& Brynjolfsson, E. (2012). Big Data: the Management Revolution. Harvard Business Review, October 2012. Retrieved from: https://hbr.org/2012/10/big-data-the-management-revolution

[31] Mc Cormick, J. (2016). Predictions 2017: Artificial Intelligence Will Drive the Insights Revolution. Forrester Research. Retrieved from: https:/www.forbes.com/sites/gilpress/2016/11/01/forresterpredicts-investment-in-artificial-intelligence-will-grow-300-in-2017/\#1 efe27da5509 
[32] Open Data Barometer (2016) Retrieved from: https://opendatabarometer.org/?_year=2017\&indicator=ODB

[33] Open Data Portal of Republic of Serbia (2018). Retrieved from: https://data.gov.rs

[34] SAS Institute, Inc. (2017a). Becoming a data-driven organization, white paper, IFL Science

[35] SAS Institute, Inc. (2017b). Roles and Responsibilities in Data Management for Big Data, presented by Information Management

[36] Schniederjans, M.J., Schniederjans, D.G. Starkey, C.M (2015). Business Analytics - Principles, Concepts, and Applications with SAS: What, Why, and How. New Jersey, USA: Pearson Education, Inc.

[37] Shashikiran, P.B., (2018). The Amazing Analytics Journey. Analytics, Jul/August 2018, 50-54, DOl.org/10.1287/LYTX.2018.04.12

[38] Siegel, E. (2016). Predictive Analytics - The power to predict who will click, buy, lie, or die, Hoboken, New Jersey: John Wiley \& Sons, Inc.

[39] Srujana, H.M., Sanjay S. Sharma \& Amitava, D. (2016). Democratization of analytics: New frontier of data economy. Analytics, March/April 2016, 42-50, Retrieved from: http://analyticsmagazine.org/democratization-of-analytics-new-frontier-of-data-economy/

[40] Tyler technologies, Inc. (2018). The Future of Connected Governmen., Retrieved from: https://www.tylertech.com/products/socrata/The-Future-of-Connected-Government.pdf

[41] Ventana Research (2015). Next-generation Predictive Analytics: Using Forward-Looking Insights to gain Competitive advantage. Research Report Executive Summary. Retrieved from: http://www.digintel.net/wp-content/uploads/2017/10/Ventana-Report-Pred.-Analytics-1.pdf

[42] Vlamis, T. (2015). The Four Realms of Analytics. Retrieved from:

http://www.vlamis.com/blog/2015/6/4/the-four-realms-of-analytics.html

[43] Walker, J. \& Simperl, E. (2018). Analytical Report 10: Open Data and Entrepreneurship. European Data Portal, February 2018, Retrieved from: https://www.europeandataportal.eu/sites/default/files/ analytical_report_10_open_data_and_entrepreneurship.pdf

[44] Weldon, D. (2017). 6 trends shaping the future of data analytics. Retrieved from: https://www.informationmanagement.com/slideshow/october-top-reader-pick-6-trends-shaping-the-future-of-data-analytics\#slide-1

[45] Zikopoulos, P.C., Eaton, C., de Roos, D., Deutch, T., \& Lapis, G., (2012). Understanding Big Data, Analytics for Enterprise Class Hadoop and Streaming Data. New York: McGraw-Hill

Received: 2019-01-22

Revision requested: 2019-03-22

Revised: 2019-04-23 (2 revisions)

Accepted: 2018-05-07

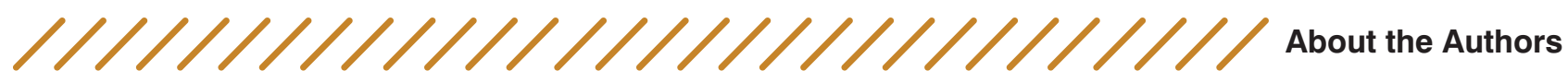

\section{Jasna Soldić-Aleksić \\ University of Belgrade, Faculty of Economics, Serbia jasnasol@ekof.bg.ac.rs}

Soldić-Aleksić Jasna holds a position of Full professor at the Department of Mathematics and Statistics, Faculty of Economics, University of Belgrade. Her main subjects of interest and research are: applied data analysis, business data management and software applications. She has gained research experience at the London School of

Economics and Political Science, Central European University in Budapest, Limburg

Business School, Belgium; Faculty of Management Science and Information Systems,

State University of New York. She is a member of the following professional bodies: International Association of Statistical Computing, Statistical Association of the Republic

of Serbia, Serbian Association of Economists, Serbian Marketing Association SEMA. She has published a number of books on the subject of applied data analysis and over 100 articles in the relevant scientific and professional journals.

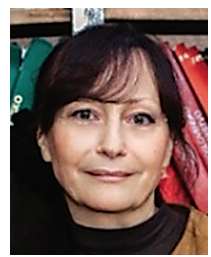


Biljana Chroneos Krasavac University of Belgrade, Faculty of Economics, Serbia biljanak@ekof.bg.ac.rs

Chroneos Krasavac Biljana, a PhD in Business Administration, was born in 1964 in Novi Sad. Ms. Chroneos Krasavac worked in numerous projects funded by the US Government, and/or the USAID. In August 2006, she was appointed by the Government of the Republic of Serbia as Serbia's Representative with the World Bank in Washington.

In addition to the experience gained at the World Bank, she has also gained several years long experience by working for the Government in the capacity of Special Advisor to the Minister of Finance and Advisor to the Director of the Flood Affected Areas Assistance and Rehabilitation Office. Currently, she is holding the position of the Director of the World Bank project "Inclusion and Early Childhood Development".

Ema Karamata

University of Belgrade, Faculty of Economics, Serbia ema.karamata@gmail.com

Karamata Ema had graduated from the University of Belgrade, Faculty of Economics, where she has also gained her Master's Degree, and where she is currently enrolled as

a PhD student at the Business Management department. The main areas of Ema's interests and expertise are: business management, information technologies, digital marketing, and data analysis. She has participated in a number of projects in the domain of business management, and conducted several surveys. Ema is currently employed at the Scientific-Research Centre at the Faculty of Economics as the

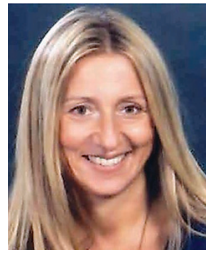
Associate in the International projects sector. 